\title{
Transcutaneous estimation of arterial carbon dioxide in intensive care. Which electrode temperature?
}

\author{
G CHERIYAN, P HELMS, F PAKY, D MARSDEN, AND M C CHIU \\ Hospital for Sick Children, Institute of Child Health, London
}

SUMMARY Transcutaneous and arterial carbon dioxide were measured simultaneously in 57 children (age range 10 days to 14.3 years) undergoing intensive care. All were haemodynamically stable at the time of study. Mean calibration time with 5 and $10 \%$ carbon dioxide was 43 (range 38-58) minutes and mean arterialisation time was 10.5 (range 3-30) minutes.

Duplicate hourly arterial samples over a four hour period showed that transcutaneous: arterial carbon dioxide correlation was independent of electrode temperatures over the range $42-44^{\circ} \mathrm{C}$ and was independent of child age. One and a half hours after electrode placement transcutaneous carbon dioxide $(\mathrm{kPa})=$ arterial carbon dioxide $\times 1 \cdot 41+0 \cdot 02$. Use of a simple ratio (arterial carbon dioxide $=$ transcutaneous carbon dioxide/1.40) resulted in a mean estimate of arterial carbon dioxide within $3 \%$ of the actual value with coefficients of variation of 11 and $15 \%$ at 1.5 and 4.5 hours, respectively.

For prediction of arterial carbon dioxide $95 \%$ confidence limits around the regression mean rose from $\pm 1.04 \mathrm{kPa}(7.8 \mathrm{~mm} \mathrm{Hg})$ at 1.5 hours to $\pm 1.56(11.7 \mathrm{~mm} \mathrm{Hg})$ at $4.5 \mathrm{hours}$. Baseline drift was more than $\pm 0.67 \mathrm{kPa}(5 \mathrm{~mm} \mathrm{Hg})$ during $22 \%$ of the studies. For a drift of less than $0.67 \mathrm{kPa}$ $95 \%$ confidence limits were 0.87 and $1.12 \mathrm{kPa}$, respectively.

Arterial carbon dioxide can be estimated with clinically acceptable tolerances from surface electrodes operating at temperatures between $42-44^{\circ} \mathrm{C}$. Improved electrode stability and speed of calibration should make this a valuable monitoring technique.

Continuous measurements of transcutaneous oxygen with electrochemical sensors are widely used in neonatal intensive care ${ }^{1}$ and are gaining acceptance in adult and paediatric intensive care. . $^{2-8}$

Transcutaneous carbon dioxide monitoring is less well established. ${ }^{1368}$ The main impact of continuous blood gas monitoring has been in the care of critically ill neonates. Non-invasive continuous estimation of arterial carbon dioxide should be useful in older children requiring intensive care. Transcutaneous carbon dioxide can be measured with glass pH electrodes using the StowSeveringhaus principle. $^{9}$ Transcutaneous carbon dioxide is greater than arterial carbon dioxide because of the effects of heating, which increases carbon dioxide tension of capillary blood and local tissue metabolism. Heat also changes the structure of the stratum corneum, allowing faster diffusion to the skin surface, and decreases the solubility of carbon dioxide, thus increasing tissue release. ${ }^{9-11}$ In addition, the rising limbs of dermal capillaries that parallel the descending venous limbs set up a counter current exchange mechanism, resulting in a diffusion gradient towards the arterial limb. ${ }^{12}$ These effects can be 'corrected' by establishing transcutaneous:arterial carbon dioxide relations in vivo and adjusting calibration values as appropriate. This approach has been used in children where a correction factor of 1.61 was found to be adequate at an electrode temperature of $44^{\circ} \mathrm{C} .{ }^{13}$

The aims of our study were to evaluate the relation between transcutaneous and arterial carbon dioxide in haemodynamically stable children undergoing intensive care, to observe the effects of changing electrode temperature to this relation, and to assess the in vivo stability of one of the commercially available electrodes.

\section{Material and methods}

Simultaneous transcutaneous and arterial carbon dioxide measurements were made in 57 children aged 10 days to 14.3 years (mean 3.5 years). All required respiratory support, 51 requiring full ven- 
tilation and six continuous distending pressure. All had indwelling arterial lines and were haemodynamically stable as assessed by continuous direct blood pressure records and peripheral to core temperature gradients. Two Roche Kontron 634 electrodes at different temperatures were used in an overlapping design to provide 16-33 studies at electrode temperatures between $42-45^{\circ} \mathrm{C}$. Subjects were randomly allocated to studies at $45 / 44,44 / 43$, or $43 / 42^{\circ} \mathrm{C}$.
Electrodes were placed on the upper chest, where they were left for 4.5 hours, and sites were inspected 24 and 48 hours after each study.

Arterialisation was assumed to be complete 30 minutes after electrode placement when the first arterial sample was taken and the time taken for a stable transcutaneous carbon dioxide value to be achieved noted. A further four samples were taken at hourly intervals. Differences between trans-

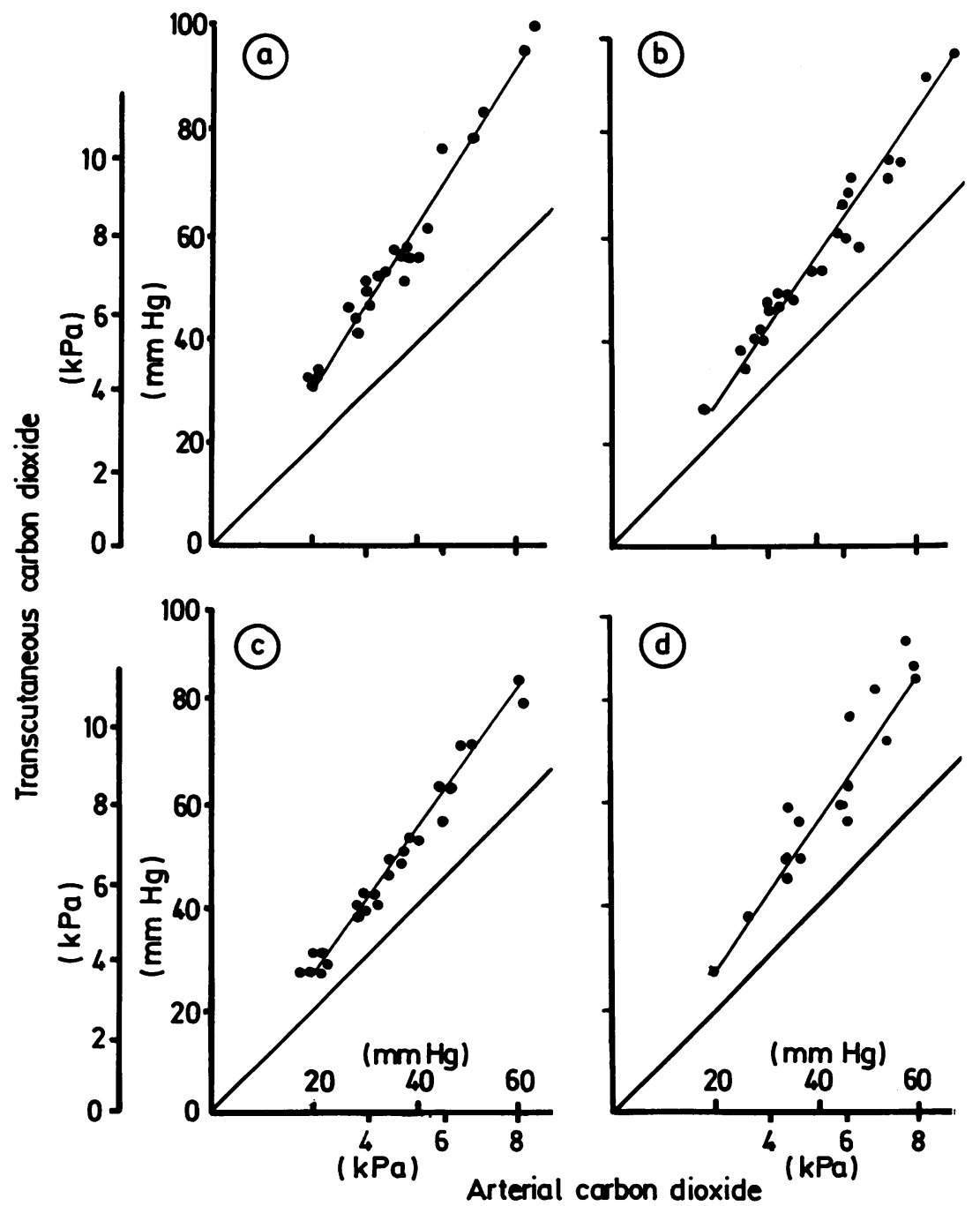

Fig. 1 Scattergrams of transcutaneous:arterial carbon dioxide relations at four different electrode temperatures. All data at one hour after arterialisation. The lines of identity and least square regressions are drawn. (a) Electrode temperature $45^{\circ} \mathrm{C}$.

Transcutaneous carbon dioxide $(k P a)=$ arterial carbon dioxide $\times 1 \cdot 61+0 \cdot 17 ;(b)$ Electrode temperature $44^{\circ} \mathrm{C}$.

Transcutaneous carbon dioxide $(k P a)=$ arterial carbon dioxide $\times 1.41+0.01 ;$ (c) Electrode temperature $43^{\circ} \mathrm{C}$.

Transcutaneous carbon dioxide $(\mathrm{kPa})=$ arterial carbon dioxide $\times 1.43-0 \cdot 16 ;(d)$ Electrode temperature $42^{\circ} \mathrm{C}$.

Transcutaneous carbon dioxide $(k P a)=$ arterial carbon dioxide $\times 1 \cdot 40+0 \cdot 01$. 
cutaneous and arterial carbon dioxide at different electrode temperatures were tested for significance by analysis of covariance for slope and for mean differences around a common regression slope. ${ }^{14}$ Possible differences with time were assessed by comparing transcutaneous:arterial carbon dioxide -relations at arterialisation and at subsequent hourly intervals up to 4.5 hours. The study had the consent of the hospital ethical committee, and informed consent was obtained from one or both parents.

Two point calibrations were performed with $5 \%$ and $10 \%$ carbon dioxide before and after each study to assess baseline drift. Time base records of transcutaneous carbon dioxide were available in all children and data were only used if these records showed stable values $( \pm 0.3 \mathrm{kPa})$ two minutes either side of an arterial sample. Arterial gas tensions were measured on an IL613 machine, which was calibrated twice daily with reference solutions and checked once weekly with tonometered blood.

\section{Results}

Mean time for in vitro stabilisation was 11 minutes (range four to 30 minutes) for all four electrode temperatures. Mean time for two point calibration was 41 minutes (range 28-58 minutes). Transcutaneous carbon dioxide was linearly related to arterial carbon dioxide over the range of arterial carbon dioxide tensions found in our population $(2 \cdot 7-10.7 \mathrm{kPa})$. Scattergrams and least square regressions for transcutaneous carbon dioxide on arterial carbon dioxide for the four electrode temperatures are shown in Figure 1. Analysis of variance for slopes and means showed no significant differences for electrode temperatures $42-44^{\circ} \mathrm{C}$. Data at $45^{\circ} \mathrm{C}$ did have a significantly higher mean $(p<0.01)$, although the regression slope was not significantly different from data at other electrode temperatures. As data over the electrode temperature range $42-44^{\circ} \mathrm{C}$ were not significantly different these were combined to produce common regression slopes.
These combined data produced regression equations that were not significantly different for slope or mean over the first 2.5 hours. As these calculated least square regression lines had insignificant intercepts mean transcutaneous:arterial carbon dioxide ratios were calculated. This ratio (mean 1.40) was not significantly different from hour to hour over the whole sampling period, although the scatter about the mean did increase with time (Table 1). Data for hours 3 and 4 were not significantly different from each other but were different from data over the first two hours for regression slopes but not for transcutaneous:arterial ratios. Further evidence for the validity of using the transcutaneous:arterial ratio to 'correct' transcutaneous carbon dioxide was also provided by the lack of any significant correlation between the ratio and arterial carbon dioxide.

When the mean transcutaneous:arterial carbon dioxide ratio of 1.40 was used to 'correct' all transcutaneous data the arterial carbon dioxide could be estimated with greater accuracy over the first 2.5 hours than over the subsequent two hours. The coefficient of variation of the estimate from least square regressions increased from $10.9 \%$ at arterialisation to $15.2 \%$ at 4.5 hours (Table 1 ). The 'corrected' transcutaneous values (transcutaneous carbon dioxide/1.40) were also directly compared with simultaneous arterial values and were capable of predicting arterial carbon dioxide with a $95 \%$ confidence interval of $\pm 0.93 \mathrm{kPa}(7 \mathrm{~mm} \mathrm{Hg})$ for hours 1 and 2 and $\pm 1.47 \mathrm{kPa}(11 \mathrm{~mm} \mathrm{Hg})$ for hours 3 and 4.

Recalibration at the end of each study showed baseline drift of more than $0.67 \mathrm{kPa}(5 \mathrm{~mm} \mathrm{Hg})$ for 27 of the 114 studies $(22 \%)$. In vitro $90 \%$ response times were not significantly different for 43,44 , and $45^{\circ} \mathrm{C}$ at $72 \pm 15$ seconds. In vitro response times were longer at the electrode temperature of $42^{\circ} \mathrm{C}$ (120 \pm 22 seconds).

We found a $22 \%$ incidence of burns at 48 hours (five of 23) for the highest electrode temperature of $45^{\circ} \mathrm{C}$. At all other temperatures mild erythema was occasionally noted at 24 hours with no residual signs at 48 hours.

Table 1 Transcutaneous:arterial carbon dioxide relations at arterialisation and at hourly intervals thereafter

\begin{tabular}{|c|c|c|c|c|c|c|}
\hline & $n$ & $\begin{array}{l}\text { Correlation } \\
\text { coefficient }\end{array}$ & Slope & $\begin{array}{l}\text { Intercept } \\
(k P a)\end{array}$ & $\begin{array}{l}\text { Standard error } \\
\text { of estimate } \\
(k P a)\end{array}$ & $\begin{array}{l}\text { Transcutaneous:arterial } \\
\text { ratio }(S D)\end{array}$ \\
\hline 1 & 76 & 0.95 & 1.41 & 0.02 & 0.70 & $1.42(0.15)$ \\
\hline 2 & 76 & 0.90 & 1.47 & -0.03 & 0.98 & $1.40(0.21)$ \\
\hline 3 & 76 & 0.88 & $1 \cdot 19$ & 1.04 & 0.98 & $1.40(0.19)$ \\
\hline
\end{tabular}




\section{Discussion}

In children requiring respiratory support and who are not in shock arterial carbon dioxide can be estimated from surface electrodes, with a $95 \%$ accuracy of roughly $\pm 1 \cdot 3 \mathrm{kPa}(10 \mathrm{~mm} \mathrm{Hg})$. If electrodes were to be calibrated once every 12 hours-that is, after two site changes-and if a constant drift of the size seen in our study is assumed the accuracy of estimation of arterial carbon dioxide should be in the order of $\pm 2.6 \mathrm{kPa}(20 \mathrm{~mm} \mathrm{Hg})$ at the end of that extended period. Improved electrode stability and single point calibrations between site changes should, however, further reduce the error of estimation of arterial carbon dioxide. If those studies with a drift of more than $0.67 \mathrm{kPa}$ are excluded arterial carbon dioxide could be estimated to within 0.85 and $1.12 \mathrm{kPa}$ at 1.5 and 4.5 hours, respectively. Electrode temperatures of $44-43^{\circ} \mathrm{C}$ are less likely to give rise to burns and have an acceptable in vitro response time. The use of the simple ratio (arterial carbon dioxide $=$ transcutaneous carbon dioxide/1.40) resulted in a mean estimate of arterial carbon dioxide within $3 \%$ of the actual value (Table 2) and indicates that such ratio 'corrected' transcutaneous carbon dioxide readings are clinically acceptable. This is a reflection of the small intercepts found in our data, a situation in which ratio standards result in minimal errors. ${ }^{15}$

Our correction factor of 1.40 for electrode temperatures $44-42^{\circ} \mathrm{C}$ is lower than that of 1.61 reported by Monaco et al. ${ }^{13}$ They, however, used a single temperature of $44^{\circ} \mathrm{C}$ and a different type of electrode (Novametrix 818). Their data at $44^{\circ} \mathrm{C}$ agrees closely with ours at $45^{\circ} \mathrm{C}$ and could be due to design differences such as the surface area of the heating coil and the position of the sensing thermistor.

Table 2 Transcutaneous:arterial carbon dioxide reiations at arterialisation and at hourly intervals thereafter corrected using arterial carbon dioxide $=$ transcutaneous carbon dioxide 1.40 ratio

\begin{tabular}{|c|c|c|c|c|c|c|}
\hline & $n$ & $\begin{array}{l}\text { Correlation } \\
\text { coefficient }\end{array}$ & Slope & $\begin{array}{l}\text { Intercept } \\
(k P a)\end{array}$ & $\begin{array}{l}\text { Standard error } \\
\text { of estimate } \\
(\mathrm{kPa})\end{array}$ & $\begin{array}{l}\text { Transcutaneous:arterial } \\
\text { ratio }(S D)\end{array}$ \\
\hline $\begin{array}{l}\text { Arterialisation } \\
\text { Hour: }\end{array}$ & 63 & 0.94 & 1.04 & -0.34 & $0 \cdot 50$ & $0.97(0.11)$ \\
\hline 1 & 76 & 0.95 & 1.01 & 0.01 & 0.50 & $1.01(0.10)$ \\
\hline 2 & 76 & 0.90 & 1.05 & -0.21 & $0 \cdot 70$ & $1.00(0 \cdot 15)$ \\
\hline 3 & 76 & $0 \cdot 88$ & 0.85 & 0.75 & 0.70 & $1.00(0 \cdot 13)$ \\
\hline
\end{tabular}
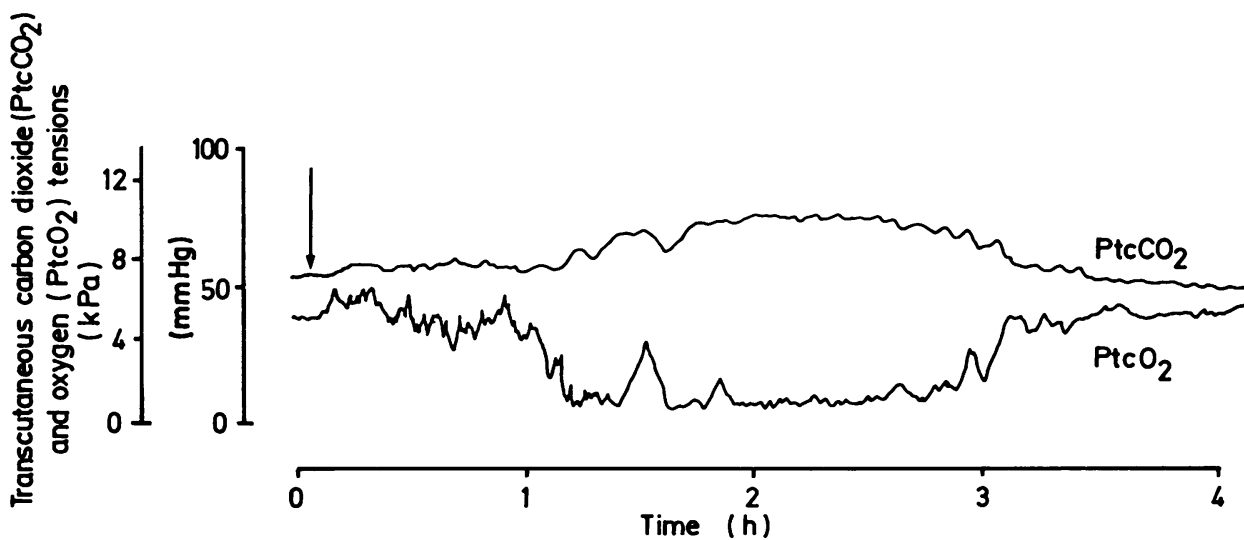

Fig. 2 Transcutaneous carbon dioxide and oxygen traces over a four hour period in an 8 month old girl with Beckwith's syndrome and associated intermittent upper airway obstruction. The degree of hypercarbia and hypoxia can be clearly seen. The carbon dioxide electrode was heated to $43^{\circ} \mathrm{C}$ and the oxygen electrode to $44^{\circ} \mathrm{C}$ and carbon dioxide calibration performed with a 'correction' of calibration carbon dioxide tension/1 40 . Arterialised capillary gases (arrow) showed an oxygen tension of $7 \cdot 1 \mathrm{kPa}$ (transcutaneous oxygen $5.4 \mathrm{kPa}$ ) and a carbon dioxide tension of $7.3 \mathrm{kPa}$ (transcutaneous carbon dioxide $7 \cdot 3 \mathrm{kPa}$ ). 
This disparity of results, at an apparently identical operating temperature, suggests that results from one machine type should not be applied to all others. This is also likely to effect results from the newer combined oxygen/carbon dioxide electrodes. The close agreement over the range $44-42^{\circ} \mathrm{C}$ does suggest that avoiding the higher effective temperatures should result in comparable results for all different machine types. For the type of electrode we used an operating temperature of $43^{\circ} \mathrm{C}$ would be ideal.

We have found the technique useful in showing episodes of retention of carbon dioxide in children with obstructive upper airway problems (Figure 2). Improved electrode stability and speed of calibration should make this a valuable non-invasive monitoring and investigative technique.

\section{References}

${ }^{1}$ Cassidy G. Transcutaneous monitoring in the newborn infant. J Pediatr 1983;103:837-48.

2 Yip WC, Tay JS, Wong HB, Ho TF. Reliability of transcutaneous oxygen monitoring of critically ill children in a general pediatric intensive care unit. Clin Pediatr (Phila) 1983;22:431-5.

${ }^{3}$ Monaco F, Nickerson BG, McQuitty JC. Continuous transcutaneous oxygen and carbon dioxide monitoring in the pediatric ICU. Crit Care Med 1982;10:765-6.

${ }^{4}$ Huch R, Huch A, Albani M, et al. Transcutaneous PO2 monitoring in routine management of infants and children with cardiorespiratory problems. Pediatrics 1976;57:681-90.
5 Yahav J, Mindorff $C$, Levison $H$. The validity of the transcutaneous tension method in children with cardiorespiratory problems. Am Rev Respir Dis 1981;124:586-7.

6 Tremper KK, Shoemaker WC, Shippy CR, Nolan LS. Transcutaneous PCO2 monitoring on adult patients in the ICU and operating room. Crit Care Med 1981;9:752-5.

${ }^{7}$ Lofgren O. Transcutaneous oxygen measurement in adult intensive care. Acta Anaesthesiol Scand 1979;23:534-44.

${ }^{8}$ Marsden D, Chiu MC, Paky F, Helms P. Transcutaneous oxygen and carbon dioxide monitoring in intensive care. Arch Dis Child 1985;68:1158-61.

${ }^{9}$ Severinghaus J, Stafford M, Bradley A. PtcO2 electrode design, calibration and temperature gradient problems. Acta Anaesthe siol Scand (Suppl) 1978;68:118-22.

${ }^{10}$ Severinghouse J, Stafford M, Thurnstrom A. Estimation of skin metabolism and blood flow with $\mathrm{PtcO} 2$ and $\mathrm{PtcCO} 2$ electrodes by cuff occlusion of the circulation. Acta Anaesthesiol Scand (Suppl) 1978;68:99-105.

11 Bradley A, Stupfel M, Severinghaus J. Effect of temperature on PCO2 and PO2 of blood in vitro. J Appl Physiol 1956;9:201-4

12 Lubbers D. Cutaneous and transcutaneous PO2 and PCO2 and their measuring conditions. In: Huch A, Huch R, Lucy S, eds. Original article series. New York: A R Liss, 1979:13.

${ }^{13}$ Monaco F, McQuitty JC, Nickerson BG. Calibration of a heated transcutaneous carbon dioxide electrode to reflect arterial carbon dioxide. Am Rev Respir Dis 1983;127:322-4.

14 Armitage P. Statistical methods in medical research. Oxford: Blackwell Scientific Publications, 1971.

15 Tanner J. Fallacy of per weight and per surface area standards and their relation to spurious correlation. J Appl Physiol 1949;2:1-15.

Correspondence to Dr P Helms, Respiratory Unit, Hospital for Sick Children, Great Ormond Street, London WC1N 3JH.

Received 7 April 1986 